WelSH OFmCE (1994) Mental Health Statistics for Wales. London: HMSO.

*Richard Duffett, Clinical Research Fellow. The Royal College of Psychiatrists Research Unit, London and Specialist Registrar Trainee, Tower Hamlets Healthcare NHS Trust, St Clement's Hospital, 2A Bow Road, London E3 4LL; Drew
Ridley Siegert, Consultant Old Age Psychiatrist, Whitchurch Hospital, Cardiff; and Paul Lelliott, Director. The Royal College of Psychiatrists Research Unit, London

*Correspondence

\title{
Treatment of the mentally ill in the Federal Republic of Germany
}

\section{Sectioning practice, legal framework, medical practice and key differences between Germany and the UK}

\author{
Hanns Rüdiger Röttgers and Peter Lepping
}

\begin{abstract}
Aims and method The legal provisions concerning the admission to hospital, holding powers and compulsory treatment of the mentally III in Germany are illustrated. The essential legal concepts are compared to the stuation in Great Britain.

Results Whereas British law gives key powers to multtprofessional decision-making and relatives, German law requests formal court decisions even in routine cases. This reflects a different understanding of individual rights and their protection. German mental health law is mottvated by the experiences of the totalitarian national sociallst regime. It tries to protect patients' rights by restricting physicians', hospltals' and family members' influence. British law, on the other hand, assumes that experts as well as family members act benevolently in the patient's interest, prefers less formal mechanisms and expresses more trust in professional ethics.

Conclusion Further research is desirable to analyse the situations in other countries and to determine which of these approaches is the most adequate from the point of view of the mentally ill. This is even more important in view of further European integration which will undoubtedly touch these questions and accelerate a convergence in medico-legal issues.
\end{abstract}

European integration will not only lead to an integration of economic markets, but also to more similar standards of the service sector, professions and jurisdiction. Whereas the medical and scientific standards in Great Britain and Germany are comparable, fundamental differ- ences exist in medico-legal concepts and the psychiatric practice as far as sectioning, forced treatment and guardianship issues are concerned. This has recently been highlighted by several High Court decisions.

\section{Sectioning law and Guardianship law in Germany}

In the Federal Republic of Germany there is a separation between public and civil law regarding Sectioning and Guardianship.

Public law is the domain of the 16 Federal States, each of which has a different sectioning law (Unterbringungsgesetz). Its function is to avert dangers to public order and security relating to mentally ill persons. Public law does not care about individual welfare or health. Guardianship law (Betreuungsgesetz) as part of the civil law on the other hand is Identical in all 16 Federal States.

Its function is to grant the proper personal. medical and economic care for those people not able to do so themselves due to handicap or illness. A guardian appointed by the local court then takes care of such persons. The guardian's rights have to be specified according to the circumstances of the individual case. Those rights can for example comprise "financial issues with the exception of everyday transactions up to DM100 per week" or "psychiatric treatment 
including hospitalisation". The necessity of guardianship and the extent of the guardians' rights have to be re-evaluated by the court at least every five years, usually in much shorter intervals.

Guardianship is to be established as restrictively as possible as it represents an infringement to personal rights. A recent decision of the supreme court of Bavaria (BayObLG 16.12.95, 3 $Z$ 343/94) consequently states that in the case of recurrent psychiatric disorders guardianship must be terminated at the end of an acute phase of illness as soon as the individual power of decision-making is re-established.

\section{Hospitalisation procedures}

Under German public law the only reason for sectioning is the acute direct danger that the patient may present to himself or others which must be secondary to a mental illness and not otherwise avoidable. The parties involved in the procedure are the city council, the local court. the patient, and a physician functioning as an aid to the court but without any power of decision. The physician's role is to find out about the diagnosis and possible alternatives to avoid hospitalisation. Only if those do not exist and the danger is still imminent does he or she recommend sectioning to the court. If the judge denies the necessity of sectioning the medical opinion remains without consequences.

Usually the local police or a physician caring for the patient asks the court for compulsory hospitalisation. The local court then performs this. In emergency situations a clerk of the city council who needs later legal confirmation by the local court can enforce hospitalisation. Under guardianship law, a patient can be hospitalised by his or her guardian against his or her will if there is a danger to his health that cannot otherwise be dealt with. This, however, is only possible with the permission of the court or as an emergency decision which has to be confirmed immediately by the court. Neither physicians nor nurses possess holding powers comparable to those granted by the Mental Health Act.

In contrast British law includes not only physical, but also psychological problems for the environment of the patient, the danger of deterioration if the patient does not receive treatment, the danger of serious harm to property or the need for physical restraint as possible reasons for hospitalisation, thus rendering many more possibilities for intervention than German law.

Considering these pre-conditions one would expect that the numbers of people being detained differ significantly in Britain and the Federal Republic of Germany. Unfortunately, only insufficient data exist. One of the reasons is the great difference between German Federal States (the number of compulsory hospitalisations varies between 9.4 and 108.8 cases per 100000 inhabitants annually). However, a hypothetical mean of the German data would come very close to the British mean of 55 compulsory hospitalisations per 100000 inhabitants annually.

\section{Compulsory treatment}

German Public law does not provide any legal basis for treatment against the patient's will. Of course the different Federal States laws define a constitutional right of the sectioned patient to receive adequate medical treatment. However, they either do not mention the difficult question of treatment against the patient's will or they merely state the obligation to tolerate emergency measures if they relate to the illness that made sectioning necessary (Eberhard, 1988; Deutsch, 1991: Riedel et al, 1992). When in doubt one has to refer to the guardianship law (Rudolf \& Röttgers, 1997). Even under guardianship conditions treatment obligations are limited. Every potentially dangerous measure including anaesthesia and long-term neuroleptic treatment has to be specifically authorised by the local court. In any case of doubt, the patient's individual right of self-determination has to be respected. A German Supreme Court decision explicitly states the "right to be ill" and to maintain a mental illness (BVerfGE 58, 208, 226ff) as long as this represents no acute danger.

The contrast with the situation in Great Britain is obvious. Being sectioned usually includes the duty to tolerate treatment. Even in the case of long-term drug application or electroconvulsive therapy, the patient's missing consent can be overruled by the opinion of a second psychiatrist. Only in the case of psychosurgical treatment and surgical implantation of hormone depots to reduce male sex drive is the consent of the patient obligatory (Part IV, Section 56-61 of the Mental Health Act 1983).

\section{Discussion}

There are significant differences between the laws regarding mental illness between Germany and Great Britain. Contributing to this are the different traditions of law. British jurisdiction is based on the case-centred Common Law whereas Germany follows the continental tradition of codified law.

In addition to this, Germany gives high priority to a formalised protection of individual civil liberties and rights due to the experiences of human rights' violations in recent German history. Above all the National Socialist dictatorship from 1933 and 1945 has to be mentioned. 
These experiences were re-enforced by the abuse of psychiatry to silence political opponents in the former East Germany.

Without the experience of totalitarian dictatorship and abuse Great Britain chooses a very pragmatic approach towards involuntary hospitalisation and treatment assuming that experts and relatives act benevolently in the patient's interest. From a German point of view it is remarkable that in Great Britain experts have rights in decision-making processes. Decisions can be made by social workers, community psychiatric nurses, doctors and relatives, whereas in Germany courts have the decision monopoly. In Britain the function of the courts is that of control rather than of decision-making itself.

Theoretically, the German model has the advantage that a body completely independent of the medical institutions makes decisions, thus avoiding the impression of a possible conflict of interest. However, this theoretical advantage is very often not felt by the patient because of the complexity of the regulations and the big distance between the court and the hospitalised patient. Furthermore the highly formalised procedures themselves can bring about controversy and polarisation which are therapeutically undesirable.

The British model on the other hand has the advantage of an individual approach with the integration of family and carers in the decisionmaking process, as well as the hospital or the home being the location of the decision-making. However, the instrument of second opinions as instance of control puts the experts involved under a high moral and professional obligation and responsibility.

It is impossible to answer the question in which way the interests of the mentally ill are better served. Studies in the USA show the importance of the feeling that hospitalisation occurred in a fair process and is comprehensible for therapy motivation and post-discharge compliance (Lidz et al, 1995) so that the problem should not be ignored. Thus, comparative European studies about the way that sectioned patients perceive their hospitalisation and treatment would be highly desirable, with Britain and Germany being ideal locations to do this because of their different medico-legal approach.

\section{References}

DEuTsCH, E. (1991) Arzt- und Arzneimittelrecht (Medical and pharmaceutical law issues). Berlin. Heidelberg \& New York: Springer-Verlag.

EBERHARD, G. A. (1988) Hifen, Schutzmaßnahmen und Maßregelvollzug bet psychischen Krankhetten in Nordrhein-Westfalen: Handbuch PsychKG-MRVGKommunale Schriften für Nordrhein-Westfalen, Band 19. (Commentary on the Northrine-Westphalian sectioning law). Cologne: Deutscher Gemeindeverlag.

LIDZ, C. W., HOGE, S. K., GARDNER, W., et al (1995) Percetved coercion in mental hospital admissions. Archives of General Psychiatry, 62, 1034-1039.

RiEdel, R. R. SEIDL, H., HOFF, P., et al (1992) Zwangsbehandlung gegen den Willen des Patienten in der Psychiatrie (Forced treatment of psychiatric patients). Münchener Medizinische Wochenschrift, 92. 33-37.

RUDOLF, G. A. E. \& RótTGERS, H. R. (1997) Rechtsfragen in der Psychiatrie (Law issues in psychiatry). Wiesbaden: Deutscher Universitaetsverlag.

Hanns Rüdiger Röttgers, Public Health Authority, Psychiatric Department County of Verden/Lower Saxony, Lindhooper Straße 67, D-27283, Verden Aller; and Peter Lepping, Wirral and West Cheshire Community NHS Trust, West Cheshire Hospital, Liverpool Road, Chester CH2 1UL

\title{
Is specialist registrar training in cognitive therapy effective?
}

\author{
Steve Moorhead and Jan Scott
}

\begin{abstract}
Alms and method This paper describes the characteristics and outcome of the first 20 patients seen by a newly appointed specialist registrar in cognitive therapy. The outcome of the first (cases 110) and second (cases 11-20) cohorts were evaluated to assess if training had any impact on clinical effectiveness.
\end{abstract}

Results Comorbidity was common, but more patients improved following the intervention (effect size $=0.64-1.34$ ). The $25 \%$ therapy drop-out rate was comparable with previlously reported rates. Four out of five patients who dropped out had Cluster B personality disorders. The two cohorts showed similar baseline characteristics, but the second cohort showed 